\title{
GENETIC DIVERSITY OF NATURALLY DISTRIBUTED Rhododendron moulmainense Hook. f. POPULATIONS IN LAM VIEN PLATEAU, VIETNAM REVEALED BY ISSR AND SCOT MARKERS
}

\author{
LUU THE TRUNG ${ }^{1,2}$, LA ANH DUONG $^{1}$, TRAN VAN TIEN ${ }^{3}$, \\ LE NGOC TRIEU ${ }^{3}$ and PHI HONG HAI ${ }^{*}$ \\ ${ }^{1}$ Vietnamese Academy of Forest Science, Duc Thang, Tu Liem, Hanoi, Vietnam \\ ${ }^{2}$ Forest Science Institute of central Highlands and South of central Viet Nam, 09 Hung Vuong, Dalat, \\ Lam Dong, Vietnam, Vietnamese Academy of Forest Science \\ ${ }^{3}$ Faculty of Biology, Dalat University, 01 Phu Dong Thien Vuong, Dalat, Lam Dong, Vietnam \\ *E-mail:phi.hong.hai@vafs.gov.vn
}

Accepted 11 October 2020, Published online 31 December 2020

\begin{abstract}
Genetic diversity and variation of three naturally distributed Rhododendron moulmainense populations in the Lam Vien Plateau of Vietnam were analyzed using ISSR and SCoT markers separately and data from the two types of markers were then combined to show the overall results. Based on combined data, the genetic diversity parameters of the Tuyen Lam population were percentage of polymorphic bands $(P P B)=28.79 \%$; genetic heterozygosity $\left(H_{\mathrm{e}}\right)=0.1041$; Shannon index $(I)=0.1552$. The corresponding parameters were $P P B=37.88 \% ; H_{\mathrm{e}}=0.1434 ; I=0.2131$ in the Hon Nga population, and $P P B=46.21 \%$; $H_{\mathrm{e}}=0.1857 ; I=0.2709$ in the Bidoup population. At the species level in Lam Dong province, the corresponding parameters were $P P B=62.12 \% ; H_{\mathrm{e}}=0.1747 ; I=0.2756$. The average of pairwise genetic similarity coefficients among investigated individuals of Tuyen Lam population was 0.973 , of Hon Nga population was 0.911 , and of Bidoup population was 0.895 . The genetic differentiation and the number of migrants per generation among investigated populations were $G_{S T S}=0.1735$ and $N \mathrm{~m}=2.3824$ individuals, respectively. Genetic distance between Tuyen Lam and Hon Nga populations was 0.0399 , between Tuyen Lam and Bidoup populations were 0.0621, and Bidoup and Hon Nga populations were 0.0670. Data generated by both marker types and the combined revealed similar trends of genetic diversity levels among the studied populations. The SCoT data showed higher values of genetic diversity and population gene differentiation than did the ISSR data, but the latter showed higher gene differentiation among sampled individuals in the study populations. Comparing the values of Polymorphism Information Content (PIC) for discriminatory ability; Effective Multiplex Ratio (EMR) for several revealed loci and/or efficiency of the primer-marker system; Marker Index (MI) for the efficiency of used method; and Resolving Power ( $R p)$ between used techniques indicated that discriminatory ability, efficiency, and ability of the ISSR primer combinations were higher but using SCoT marker system was more efficient than ISSR marker system for evaluating genetic diversity.
\end{abstract}

Key words: Rhododendron moulmainense, ISSR, SCoT genetic diversity, Vietnam

\section{INTRODUCTION}

The genus Rhododendron belongs to Ericaceae and comprises about 1000 species (Fang \& Stevens, 2005). In Vietnam, 44 species of this genus have been recorded (Huong et al., 2012). Many Rhododendron species have been cultivated as medicinal plants and as ornamental plants for their beautiful flowers. Rhododendron moulmainense
Hook. is one of these species (Chi, 2012). Recently, the exploitation of precious plants from their natural habitats for ornamental plant/bonsai making purposes has been intensifying in Lam Dong province, in the Lam Vien plateau of Vietnam, and changes in the local ecology have been intensifying. This has exposed $R$. moulmainense to a loss in genetic diversity and if there is no conservation solution, the extinction of these species populations is only a matter of time.

* To whom correspondence should be addressed. 
Research on the genus Rhododendron in Lam Dong province by Duy et al. (2014) revealed was difficult to find seedlings and young plants of $R$. moulmainense. Populations were small and the number of individuals had continuously declined by more than $50 \%$ over 10 years. The total area of the species' distribution in Lam Dong was less than $100 \mathrm{kM}^{2}$ (Duy et al., 2014). Collating with IUCN standards, $R$. moulmainense had been listed as Vulnerable level, i.e. VU.A2a; B2b; C2b (iii, iv); $\mathrm{D} 2 \mathrm{~b}$ (iii, iv), and these researchers concluded that improved conservation measures were required to protect the species.

Genetic diversity enables plant species to evolve and adapt to climate change and changing environmental conditions. An understanding of population genetic diversity is essential for longterm conservation, development, and sustainable exploitation. Genetic diversity and genetic variation within and among populations of a species are assessed to create the basis to establish and apply suitable strategies for in-situ and ex-situ conservation and development of those populations (Hogbin \& Peakall, 1999). This approach has been applied in many plant species including several Rhododendron species such as $R$. trifolium and $R$. nivale in Tibet (Xu et al., 2017a; 2017b), $R$. aureum, $R$. protistum var. giganteum in China (Liu et al., 2012; Wu et al., 2015) and R. ferrugineum populations in Northern Apennines (Bruni et al., 2012). However, the population genetic diversity of $R$. moulmainense has not yet been studied in Vietnam.

Based on the rapid development of biotechnology, molecular markers are considered powerful tools for analysis of population genetic diversity and variation (Muhammad \& Muhammad, 2014). Various approaches are available for DNA fingerprinting, such as RAPD (Random Amplified Polymorphic DNA), AFLP (Amplified Fragment Length Polymorphism), SSR (Simple Sequence Repeat), ISSR (Inter Simple Sequence Repeat) (Kumar et al., 2009), and SCoT (Start Codon Targeted) (Collard \& Mackill, 2009). Each of those approaches possesses their, own advantages and disadvantages, but ISSR and SCoT have proved to be low-cost, simple, and easy to execute and worthy markers for population genetic diversity assessment and are considered as dominant techniques. While the ISSR technique targets DNA regions between the microsatellites which distribute either the transcribed regions or the non transcribed regions of the genome. SCoT technique targets the start codon of functional genes. However, these techniques are technically similar when using a single oligonucleotide as forward and reverse primers in PCR (Collard \& Mackill, 2009). ISSR and SCoT techniques were proposed to be used in conjunction or with other DNA fingerprinting techniques for various applications such as genetic analysis and quantitative trait loci mapping, especially in laboratories with a preference for agarose gel electrophoresis (Nagoaka \& Ogihara, 1997; Collard \& Mackill, 2009).

The main purpose of our study was to assess the genetic diversity, variation, and structure of three naturally distributed $R$. moulmainense populations in the Lam Vien plateau of Vietnam, to provide basic data for conservation and sustainable utilization of this medicinal/ornamental plant species. Also, we compared the performance of ISSR and SCoT techniques for assessing the genetic diversity of the investigated populations.

\section{MATERIALS AND METHODS}

Twenty individuals were chosen for sampling from each other at a distance of at least $200 \mathrm{~m}$ from each of three natural populations of $R$. moulmainense on the Lam Vien plateau (Lam Dong province). Fresh leaves from chosen individuals were labeled and collected separately to bring to the Plant Breeding Technology Laboratory of Dalat University for DNA extraction. Information for the collected samples is presented in Table 1.

\section{DNA extraction}

CTAB protocol I (Weising et al., 2005) was modified by adding $10 \%$ SDS to the extraction buffer, which was used to extract total genomic DNA from fresh leaves. Two to three DNA samples were extracted from each collected sample. Extracted DNA was dissolved in the TE buffer. DNA concentration and purity were measured by the Spectrophotometry method (Weising et al., 2005) using the NanoScan2 system (Analytik Jena). The DNA samples with a value of $\mathrm{OD}_{260} / \mathrm{OD}_{280}$ from

Table 1. Collected samples used in this research

\begin{tabular}{llll}
\hline Sample code & Population & Geographic localities & Longitude/Latitude \\
\hline RhC1, RhC2, .., RhC20 & Tuyen Lam & Tuyen Lam lake & $108^{\circ} 26^{\prime} 22.79 " \mathrm{E}, 11^{\circ} 52^{\prime} 13.16^{\prime \prime} \mathrm{N}$ \\
RhB1, RhB2, .., RhB20 & Hon Nga & Hon Nga mountain & $108^{\circ} 14^{\prime} 10.43^{\prime \prime} \mathrm{E}, 12^{\circ} 1^{\prime} 16.64^{\prime \prime} \mathrm{N}$ \\
RhA1, RhA2, .., RhA20 & Bidoup & Bidoup mountain & $108^{\circ} 34^{\prime} 57.43^{\prime \prime} \mathrm{E}, 12^{\circ} 9^{\prime} 12.35^{\prime \prime} \mathrm{N}$ \\
\hline
\end{tabular}


1.7 to 2.0 and closer to 1.8 were chosen for analysis in the study. DNA samples were stored at $-20^{\circ} \mathrm{C}$ for subsequent use.

\section{DNA fingerprinting}

ISSR and SCoT techniques were used to create DNA fingerprints. ISSR primers used in this study were synthesized by PhuSa Biochem Ltd. Company (Vietnam), according to the primer set suggested by the University of British Columbia and Zagazig University (Egypt) (Admed, 2005), while SCoT primers were the set published by Collard and Mackill (2009), respectively.

For each DNA fingerprinting technique, twenty randomly chosen primers were used on five randomly tested $R$. moulmainense samples to determine which yielded bright, clear bands and displayed at least one polymorphic band. Nine ISSR and nine SCoT primers met the set-out criteria and were chosen and described in Table 2. These selected primers were applied to the full set of 60 $R$. moulmainense samples.

PCRs were performed in $50 \mu \mathrm{L}$-volume, which each contained $25 \mu \mathrm{L}$ My Red HS Taq mix (Bioline), $0.2 \mu \mathrm{M}$ primer, and approximately $30 \mathrm{ng}$ DNA templates. The amplifications were with the following programs:
- For ISSR techniques: initial denaturation at $94^{\circ} \mathrm{C}$ for $5 \mathrm{~min} ; 10$ cycles of $94^{\circ} \mathrm{C}$ for $15 \mathrm{sec}$, annealing temperature $+5\left(\mathrm{~T}_{\mathrm{a}}+5\right)^{\circ} \mathrm{C}$ (Table 2) for $15 \mathrm{sec}$, decreased $0.5^{\circ} \mathrm{C} /$ cycle, $72^{\circ} \mathrm{C}$ for $45 \mathrm{sec}$; 30 cycles of $94^{\circ} \mathrm{C}$ for $15 \mathrm{sec}$, annealing temperature for $15 \mathrm{sec}, 72^{\circ} \mathrm{C}$ for $45 \mathrm{sec}$; final extension at $72^{\circ} \mathrm{C}$ for $10 \mathrm{~min}$.

- For SCoT technique: initial denaturation at $94^{\circ} \mathrm{C}$ for $5 \mathrm{~min} ; 36$ cycles of $94^{\circ} \mathrm{C}$ for $15 \mathrm{sec}$, $50^{\circ} \mathrm{C}$ for $15 \mathrm{sec}, 72^{\circ} \mathrm{C}$ for $45 \mathrm{sec}$; final extension at $72^{\circ} \mathrm{C}$ for $10 \mathrm{~min}$.

The PCR products were examined for specificity via $2.5 \%$ agarose gel electrophoresis, using TBE buffer at $70 \mathrm{~V}$ for $2.5 \mathrm{hr}$, stained with Ethidium bromide $(0.5 \mu \mathrm{g} / \mathrm{mL})$, and photographed under 254 and 312 nm wavelength lights using UVP GelStudio Plus System (Analitik Jena, Germany).

\section{Data analysis}

Since ISSR and SCoT markers are dominantly inherited, each band was assumed to represent the phenotype at a single biallelic locus (Williams et $a l ., 1990)$. The bands were scored as presence (1) or absence ( 0$)$ characters to construct the binary data matrix.

Table 2. ISSR and SCoT primers used in this study

\begin{tabular}{|c|c|c|c|c|c|c|}
\hline No. & Primer code & Sequence 3' to 5' & $\mathrm{T}_{\mathrm{a}}\left({ }^{\circ} \mathrm{C}\right)$ & $\begin{array}{c}\text { Chosen } \\
\text { after } \\
\text { screening }\end{array}$ & $\begin{array}{c}\text { Number of } \\
\text { induced } \\
\text { bands }\end{array}$ & $P P B(\%)$ \\
\hline & \multicolumn{6}{|l|}{ ISSR primers } \\
\hline 1 & UBC 17899 & $5^{\prime}-(\mathrm{CA})_{6} \mathrm{~A} / \mathrm{G}$ G-3' & 54 & $x$ & 10 & 80.00 \\
\hline 2 & HB 8 & $5^{\prime}-(\mathrm{GA})_{6}$ GG-3' & 52 & $x$ & 9 & 44.44 \\
\hline 3 & HB12 & $5^{\prime}-(\mathrm{CAC})_{3} \mathrm{GC}-3^{\prime}$ & 52 & $x$ & 9 & 55.56 \\
\hline 4 & UBC 807 & $5^{\prime}-(A G)_{8} T-3^{\prime}$ & 54 & & 6 & 50.00 \\
\hline 5 & UBC 808 & $5^{\prime}-(\mathrm{AG})_{8} \mathrm{C}-3^{\prime}$ & 52 & $x$ & 5 & 40.00 \\
\hline 6 & ISSR 814 & $5^{\prime}-(\mathrm{CT})_{8} \mathrm{TG}-3^{\prime}$ & 51.5 & $x$ & 6 & 50.00 \\
\hline 7 & UBC 842 & $5^{\prime}-(\mathrm{GA})_{8} \mathrm{~T} / \mathrm{C} \mathrm{G}-3^{\prime}$ & 51.5 & $x$ & 10 & 50.00 \\
\hline 8 & UBC856 & $5^{\prime}-(\mathrm{AC})_{8} \mathrm{~T} / \mathrm{C} \quad \mathrm{A}-3^{\prime}$ & 52 & $x$ & 5 & 60.00 \\
\hline \multirow[t]{4}{*}{9} & UBC873 & $5^{\prime}-(\mathrm{GACA})_{4}-3^{\prime}$ & 52 & $x$ & 6 & 83.33 \\
\hline & \multicolumn{4}{|c|}{ Total of ISSR technique based on selected primers } & 66 & \\
\hline & \multicolumn{4}{|c|}{ Average of ISSR technique based on selected primers } & 7.3 & 57.58 \\
\hline & \multicolumn{6}{|l|}{ SCoT primers } \\
\hline 10 & SCoT 1 & CAACAATGGCTACCACCA & 50 & $x$ & 10 & 60.00 \\
\hline 11 & SCoT 9 & CAACAATGGCTACCAGCA & 50 & & 7 & 71.43 \\
\hline 12 & SCoT 12 & ACGACATGGCGACCAACG & 50 & $x$ & 7 & 85.71 \\
\hline 13 & SCoT 13 & ACGACATGGCGACCATCG & 50 & $x$ & 6 & 50.00 \\
\hline 14 & SCoT 18 & ACCATGGCTACCACCGCC & 50 & $x$ & 7 & 57.14 \\
\hline 15 & SCoT 19 & ACCATGGCTACCACCGGC & 50 & $x$ & 6 & 83.33 \\
\hline 16 & SCoT 22 & AACCATGGCTACCACCAC & 50 & $x$ & 7 & 85.71 \\
\hline 17 & SCoT 29 & CCATGGCTACCACCGGCC & 50 & $x$ & 7 & 42.86 \\
\hline \multirow[t]{3}{*}{18} & SCoT 30 & CCATGGCTACCACCGGCG & 50 & $\times$ & 9 & 77.78 \\
\hline & \multicolumn{4}{|c|}{ Total of SCoT technique based on selected primers } & 66 & \\
\hline & \multicolumn{4}{|c|}{ Average of SCoT technique based on selected primers } & 7.3 & 68.22 \\
\hline
\end{tabular}


The basic parameters for genetic diversity were calculated with the Popgene 32 software application. These parameters comprise the percentage of polymorphic bands $(P P B)$, genetic heterozygosity/ Nei's gene diversity index $\left(H_{\mathrm{e}}\right)$, the Shannon index $(I)$, Nei's coefficient of gene differentiation $\left(G_{S T}\right)$, gene flow $(\mathrm{Nm})$, and genetic distance between populations (D) (Yeh et al., 1999). Based on genetic distances between pairs of investigated populations, the dendrogram expressing the genetic relationship among these populations was established using NTSYSpc 2.1 (Numerical Taxonomy and Multivariate Analysis System) software (Rohlf, 2004). Analysis of molecular variance (AMOVA) was carried out using the GenAlEx 6.0 program (Peakall \& Smouse, 2006) to describe the distribution of genetic variability among and within investigated populations. Pairwise genetic similarity coefficients (GSCs) among investigated samples, their average $(A G S C)$, and UPGMA dendrogram for the genetic relationship among studied samples were calculated and established by using NTSYSpc 2.1 software (Rohlf, 2000).

Genetic parameters of three investigated populations were calculated based on ISSR technique-induced data (corresponding parameters coded as $\left.P P B_{\mathrm{I}}, H_{\mathrm{eI}}, I_{\mathrm{I}}, G_{S T \mathrm{I}}, N \mathrm{~m}_{\mathrm{I}}, D_{\mathrm{I}}, G S C \mathrm{~s}_{\mathrm{I}}, A G S C_{\mathrm{I}}\right)$ and SCOT technique-induced data (corresponding parameters coded as $P P B_{S}, H_{\mathrm{eS}}, I_{\mathrm{S}}, G_{S T \mathrm{~S}}, N \mathrm{~m}_{\mathrm{S}}, D_{\mathrm{S}}$, $\left.G S C \mathrm{~s}_{\mathrm{S}}, A G S C_{S}\right)$ separately for comparison of the two DNA fingerprinting techniques. Using a data set combined from both techniques, final genetic parameters were calculated and coded as $P P B, H_{\mathrm{e}}$, $I, G_{S T}, N \mathrm{~m}, D, G S C \mathrm{~s}, A G S C$.

The criteria to compare the usability of the used techniques comprised the Polymorphism Information Content (PIC) for discriminatory ability; Effective Multiplex Ratio (EMR) for number of revealed loci and/or efficiency of the primer-marker system; Marker Index (MI) for the efficiency of used method; and Resolving Power (Rp) for the ability of the primer combination to detect the differences between investigated samples. PIC, EMR, MI, and $\mathrm{Rp}$ values for all samples were calculated based on ISSR and SCoT techniques separately using iMECan online marker efficiency calculator tools which is available at https://irscope.shinyapps.io/iMEC/ (Amiryousefi et al., 2018).

\section{RESULTS AND DISCUSSION}

ISSR technique-induced data for genetic diversity and genetic variation among and within investigated populations

A total of 66 bands were recorded with an average of 7.3 bands per primer. Genetic diversity parameters based on ISSR markers are shown in Table 3

The pairwise genetic similarity coefficients $\left(G S C \mathrm{~s}_{\mathrm{I}}\right)$ among investigated individuals of the Tuyen Lam population were between 0.758 and 0.985 with an average $\left(A G S C_{\mathrm{I}}\right)$ of 0.893 . The $G S C \mathrm{~s}_{\mathrm{I}}$ were between 0.697 and 1.000 with an average $\left(A G S C_{\mathrm{I}}\right)$ of 0.906 , and between 0.727 and 1.000 with an average $\left(A G S C_{\mathrm{I}}\right)$ of 0.883 was obtained for Hon Nga and Bidoup populations, respectively. At the species level, the pairwise genetic similarity coefficients $\left(G S C \mathrm{~s}_{\mathrm{I}}\right)$ of $60 R$. moulmainense individuals investigated in this study were between 0.667 and 1.000 with an average $\left(A G S C_{\mathrm{I}}\right)$ of 0.880 . However, 5 pairs of individuals could not be genetically distinguished.

Analyzing the DNA fingerprints induced by the ISSR technique, the genetic differentiation $\left(G_{S T I}\right)$ among $R$. moulmainense populations was estimated to be 0.1290 and the number of migrants $\left(N \mathrm{~m}_{\mathrm{I}}\right)$ was estimated as 3.3774 individuals per generation among populations. Genetic distance $\left(D_{\mathrm{I}}\right)$ between Tuyen Lam and Hon Nga populations was 0.0191, between Tuyen Lam and Bidoup populations were 0.0444 and between Hon Nga and Bidoup populations was 0.0490 . The genetic relationship among three investigated populations based on ISSR markers is presented in Figure 1.

AMOVA analysis revealed that $16 \%$ of total genetic variability was among populations and the remaining $84 \%$ portioned within populations.

SCoT technique-induced data for genetic diversity and genetic variation among and within investigated populations

The SCoT techniques also yielded 66 bands with an average of 7.3 bands per primer. Genetic diversity parameters based on SCOT markers are shown in Table 4.

Table 3. Genetic diversity parameters based on ISSR markers in the three populations

\begin{tabular}{lcccc}
\hline Parameter & Tuyen Lam & Hon Nga & Bidoup & Species-level \\
\hline$H_{\text {el }}$ & 0.1259 & 0.1293 & 0.1708 & 0.1630 \\
$l_{l}$ & 0.1885 & 0.1947 & 0.2512 & 0.2561 \\
$P P B_{1}(\%)$ & 36.36 & 36.36 & 43.94 & 57.58 \\
\hline
\end{tabular}


Table 4. Genetic diversity parameters based on SCoT markers in the three populations

\begin{tabular}{lcccc}
\hline Parameter & Tuyen Lam & Hon Nga & Bidoup & Species-level \\
\hline$H_{e S}$ & 0.0823 & 0.1574 & 0.2006 & 0.1864 \\
$I S$ & 0.1220 & 0.2316 & 0.2907 & 0.2951 \\
$P P B_{\mathrm{S}}(\%)$ & 21.21 & 39.39 & 48.48 & 66.67 \\
\hline
\end{tabular}

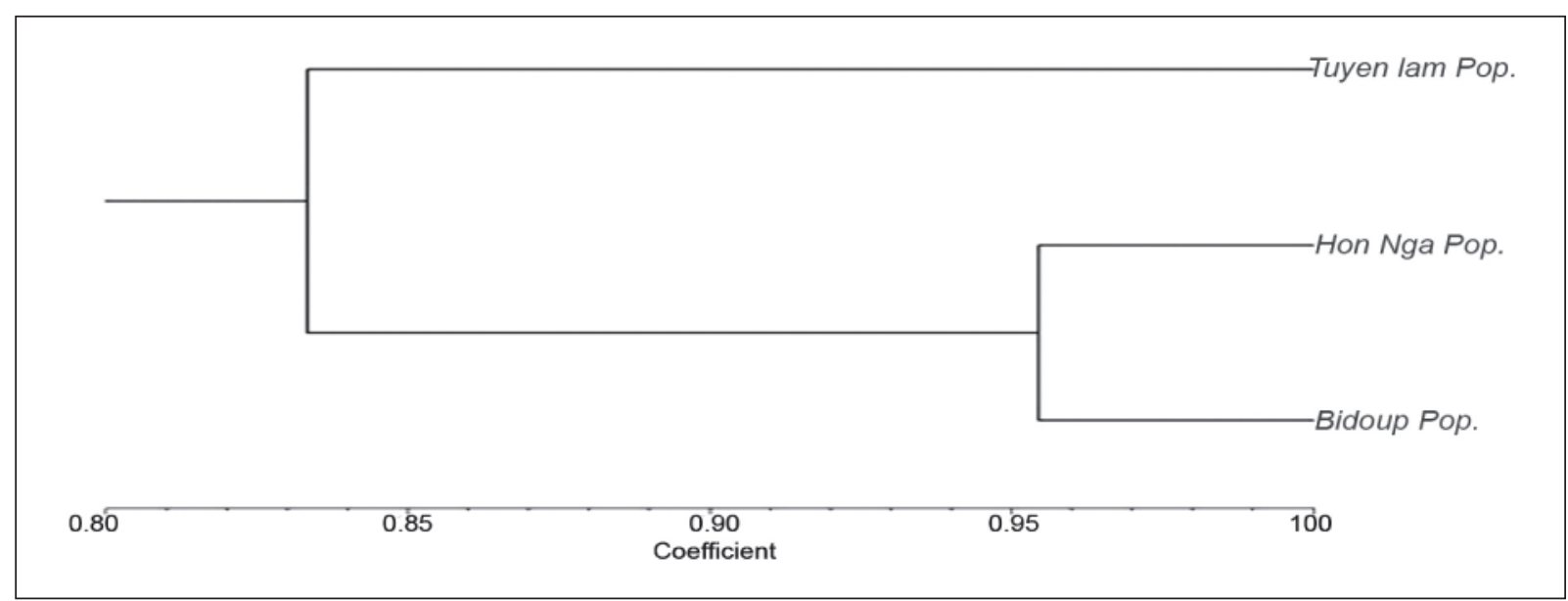

Fig. 1. Dendrogram expressing the genetic relationship among three investigated populations based on ISSR markers.

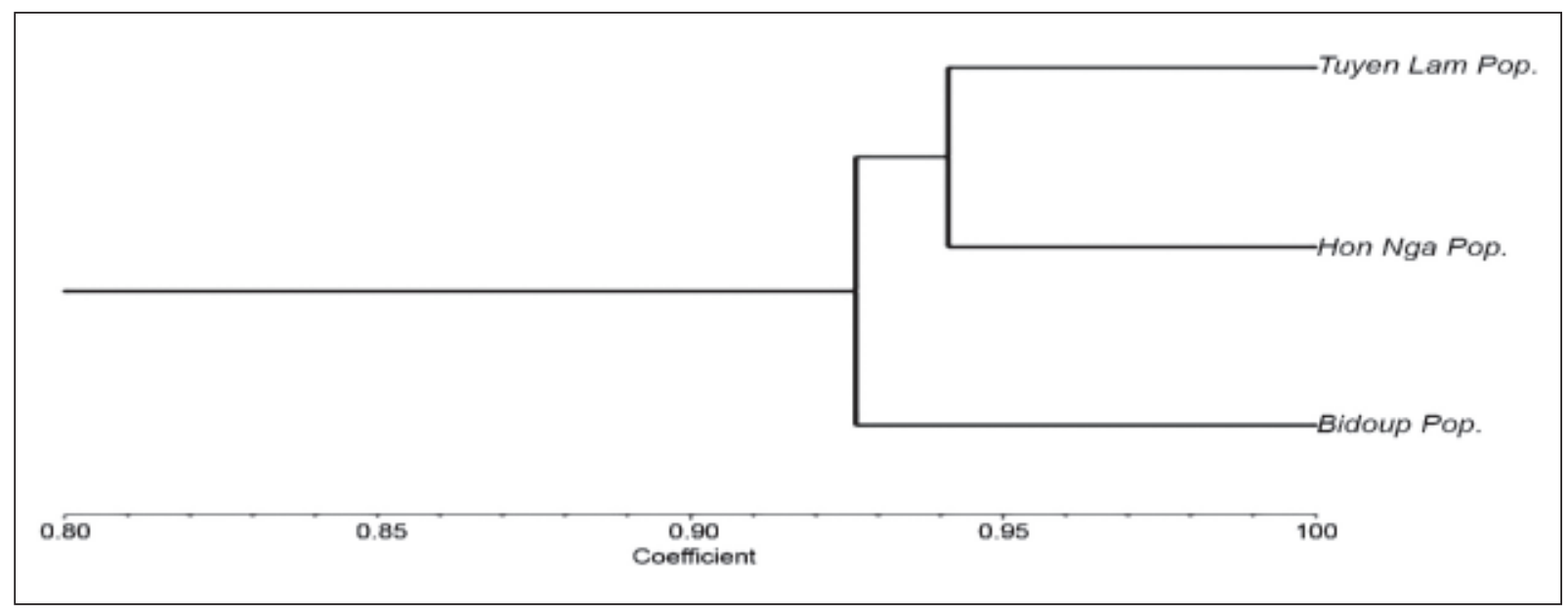

Fig. 2. Dendrogram representing the genetic relationship among three investigated populations based on SCoT markers.

The pairwise genetic similarity coefficients among investigated individuals of the Tuyen Lam population were between 0.864 and 1.000 with an average of $A G S C_{\mathrm{S}}=0.951$. Those for Hon Nga were between 0.758 and 1.000 with an average of $A G S C_{\mathrm{S}}$ $=0.916$ and those for Bidoup were between 0.652 and 1.000 with an average of $A G S C_{\mathrm{S}}=0.895$. At the species level, the pairwise genetic similarity coefficients of 60 studied $R$. moulmainense individuals investigated in this study were between 0.561 and 1.000 with an average of $A G S C_{\mathrm{S}}=0.908$. Also, 16 pairs of individuals could not be distinguished.
Based on the SCoT technique, the genetic differentiation among $R$. moulmainense populations $\left(G_{S T \mathrm{~S}}\right)$ was estimated to be 0.2124 and the number of migrants $\left(\mathrm{Nm}_{\mathrm{S}}\right)$ was estimated as 1.8539 individuals per generation among populations. Genetic distance $\left(D_{\mathrm{S}}\right)$ between Tuyen Lam population and Hon Nga population was 0.0606, between Tuyen Lam population and Bidoup population was 0.0796 and between Hon Nga population and Bidoup population was 0.0703 . The genetic relationship among three investigated populations based on SCoT markers is presented in Figure 2. 
AMOVA analysis revealed remarkable genetic differences among all three $R$. moulmainense populations, with $19 \%$ of total genetic variability portioned among populations and the remaining $81 \%$ portioned within populations.

\section{Comparison of usability between the ISSR and SCoT techniques in studied populations}

At the population level, ISSR and SCoT markers reflected the same general trend of $H_{\mathrm{e}}$ and $I$ in three investigated populations: Tuyen Lam population < Hon Nga population < Tuyen Lam population in genetic diversity, but this trend was not clear based on values for percentage of polymorphic bands. The combined data also reflected the above trend for all of $I, H_{\mathrm{e}}$, and $P P B$. Depended on each of the studied populations, $I, H_{\mathrm{e}}$, and $P P B$ values were higher either when using the ISSR technique or the SCoT technique, but based on all data sets the Bidoup population had the highest genetic diversity. DNA fingerprinting ability and characteristics of induced data of ISSR and SCoT techniques in total 60 investigated individuals are shown in Table 5.

Table 5 shows that the DNA fingerprinting ability including the rate of the chosen primers/ initially tested primers and several revealed loci was similar for the ISSR technique and SCoT techniques. Generally, SCoT technique-induced data showed higher values of genetic diversity and population gene differentiation parameters than ISSR technique-induced data. Thus, ISSR techniqueinduced data inevitably showed higher gene differentiation among investigated individuals in studied populations. These comparative results again could be recognized through the average values of Polymorphism Information Content (PIC), Effective Multiplex Ratio (EMR), Marker Index (MI), and Resolving Power (Rp) achieved from ISSR and SCoT techniques in Table 6.

Data in Table 6 shows that in this study, the average of PIC, MI, and Rp using the ISSR primers was significantly higher than using the SCoT primers. This indicated that discriminatory ability, efficiency, and ability of the primer combination when using the ISSR technique were better than using the SCoT technique. The average effective multiplex ratio (EMR) achieved from the SCoT technique was higher than from the ISSR showed that the system of the SCoT primers was more efficient than the system of the ISSR primers.

In general, in assessing the effectiveness of marker systems or DNA fingerprinting techniques in assessing population diversity and genetic variation, PIC reflects the discriminatory ability of the marker. The higher MI means the better the method and Rp is a parameter used to characterize the ability of the primer/marker combination to detect the differences between investigated genotypes. The higher the value of EMR means the more efficient the "primermarker system" (Chesnokov \& Artemyeva, 2015).

\section{Genetic diversity and genetic variation of investigated $R$. moulmainense populations based on combined data}

In previous research on population genetic diversity and genetic variation, the result generally recognized that increasing the number of investigated loci gives more reliable results (Carling \& Brumfield, 2007). There have been various studies using a combination of two or more DNA fingerprinting techniques to study population genetics (Kumar et al., 2014; Xu et al., 2017a; Agarwal et al., 2018; Talebi et al., 2018). To best exploit all the data generated in this study, we combined the ISSR and SCoT data sets. Both marker types were dominant, making combination feasible. Genetic diversity parameters of the three populations and at the species level for the combined data set are shown in Table 7. Bidoup population was the highest genetically diverse, Tuyen Lam population was the lowest genetically diverse and Hon Nga population was intermediate.

These results may be explained by the history of the three populations over recent decades. While the habitat of the Bidoup population has been protected by Bidoup Nui Ba National Park. Hon

Table 5. DNA fingerprinting ability and genetic diversity/variation revealing feature of the ISSR and the SCoT techniques in studied populations

\begin{tabular}{lcc}
\hline Criterion & ISSR technique & SCoT technique \\
\hline Rate of the chosen primers/ initially tested primers & $9 / 20$ & $9 / 20$ \\
Average number of revealed loci per chosen primer & 7.3 & 7.3 \\
Percentage of polymorphic bands $(P P B)$ & $57.58 \%$ & $66.67 \%$ \\
Expected heterozygosity $\left(H_{\mathrm{e}}\right)$ & 0.1630 & 0.1864 \\
Population gene differentiation $\left(G_{\mathrm{ST}}\right)$ & 0.1290 & 0.2124 \\
Genetic variability among populations & $16 \%$ & $84 \%$ \\
Genetic variability within individuals of populations & $19 \%$ & $81 \%$ \\
Average pairwise genetic distance of populations & 0.0375 & 0.0711 \\
Average of pairwise genetic similarity coefficient $($ AGSC) & 0.880 & 0.908 \\
\hline
\end{tabular}


Table 6. Effect of used primers and techniques in genetic diversity estimation with studied population

\begin{tabular}{llcccc}
\hline No. & Primer code & $\begin{array}{c}\text { Polymorphism } \\
\text { Information Content } \\
\text { (PIC) }\end{array}$ & $\begin{array}{c}\text { Effective Multiplex } \\
\text { Ratio (EMR) }\end{array}$ & $\begin{array}{c}\text { Marker } \\
\text { Index (MI) }\end{array}$ & $\begin{array}{c}\text { Resolving } \\
\text { Power (Rp) }\end{array}$ \\
\hline 1 & UBC 17899 & 0.1941 & 6.8333 & 0.0049 & 2.0000 \\
2 & HB 8 & 0.2387 & 7.2500 & 0.0042 & 1.7667 \\
3 & UBC 807 & 0.2598 & 7.7667 & 0.0034 & 0.7333 \\
4 & HB12 & 0.2366 & 4.8000 & 0.0043 & 1.1333 \\
5 & UBC 808 & 0.2454 & 4.1167 & 0.0040 & 0.5667 \\
6 & ISSR 814 & 0.2674 & 5.3167 & 0.0030 & 1.0333 \\
7 & UBC 842 & 0.2773 & 9.2167 & 0.0022 & 1.3000 \\
8 & UBC856 & 0.2861 & 4.8500 & 0.0009 & 0.3000 \\
9 & UBC873 & 0.2083 & 4.3500 & 0.0048 & 1.5000 \\
& Average of ISSR technique & 0.2460 & 6.0556 & 0.0035 & 1.1481 \\
\hline 10 & SCoT 1 & 0.1091 & 9.8833 & 0.0004 & 0.2333 \\
11 & SCoT 9 & 0.1053 & 6.6667 & 0.0014 & 0.6667 \\
12 & SCoT 12 & 0.0932 & 6.3000 & 0.0027 & 1.4000 \\
13 & SCoT 13 & 0.0963 & 5.4667 & 0.0025 & 1.0667 \\
14 & SCoT 18 & 0.1089 & 6.8833 & 0.0005 & 0.2333 \\
15 & SCoT 19 & 0.1039 & 5.6667 & 0.0017 & 0.6667 \\
16 & SCoT 22 & 0.1049 & 6.6500 & 0.0015 & 0.7000 \\
17 & SCoT 29 & 0.0952 & 6.3500 & 0.0025 & 1.2333 \\
18 & SCoT 30 & 0.0991 & 6.3000 & 0.0022 & 1.4000 \\
& Average of SCoT technique & 0.1018 & 0.0017 & 0.8444 \\
\hline
\end{tabular}

Table 7. Genetic diversity parameters based on combined data in the three populations

\begin{tabular}{lcccc}
\hline Parameter & Tuyen Lam & Hon Nga & Bidoup & Species-level \\
\hline$H_{e S}$ & 0.1041 & 0.1434 & 0.1857 & 0.1747 \\
IS & 0.1552 & 0.2131 & 0.2709 & 0.2756 \\
$P P B_{\mathrm{S}}(\%)$ & 28.79 & 37.88 & 46.21 & 62.12 \\
\hline
\end{tabular}

Nga population has been surrounding by rapidly extending agricultural regions and the Tuyen Lam habitat has declined in the area, extent, and quality due to the expansion of nearby agriculture and tourism (Figure 1).

There are several reviews of population genetics in a wide range of plants that possess similar lifehistory traits to $R$. moulmainense, i.e. dicotyledons, long-lived perennial, regional distribution, a breeding system of outcrossing, and with seed dispersal by gravity. Studies by Hamrick and Godt (1996) using allozyme markers which showed $H_{\mathrm{e}}=0.128-0.190$, while Nybom and Bartish (2000) used RAPD markers which showed $H_{\mathrm{e}}=0.191-$ 0.260 . Comparing to these previous studies, the genetic diversity of the currently studied $R$. moulmainense population was much lower.

Comparing with other studies within the genus Rhododendron, including seven deciduous Azalea species (Rhododendron spp. section Pentanthera) native to the Eastern United States investigated by Chappell et al. (2008) using AFLP technique; six
$R$. trifolium populations sampled from Tibetan assessed by Xu et al. (2017a) using ISSR and AFLP techniques; four $R$. aureum Georgi populations in Changbai Mountain, China using ISSR and RAPD techniques by Liu et al. (2012); R. arboreum in temperate forest and the tropical forests of India populations using RAPD technique by Kuttapetty et al. (2014), the genetic diversity parameters values obtained in this study for each investigated population and species level were lower. Genetic diversity was similar when comparing the ISSR technique-induced genetic diversity parameters obtained in this study with the corresponding parameters based on ISSR techniques in studies of $\mathrm{Xu}$ et al. (2017a) and Liu et al. (2012). However, the $H_{\mathrm{e}}$ values obtained for three populations in the current study were medium to high compared to six invasive populations in Ireland and twelve native populations in Georgia and Spain of $R$. ponticum species in a study using AFLP markers conducted by Erfmeier and Bruelheide (2011). 


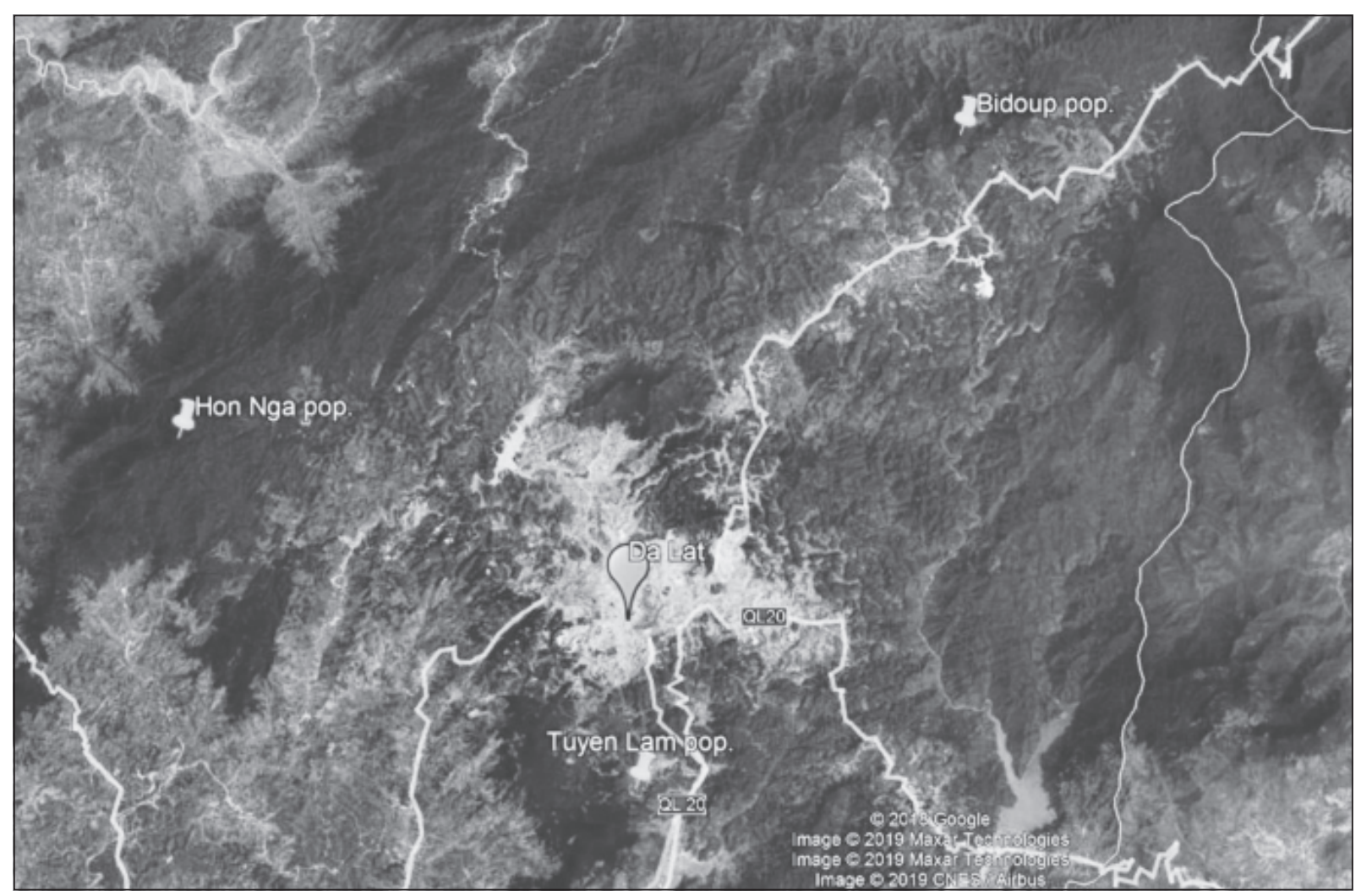

Fig. 3. Distribution of three investigated R. moulmainense populations.

Based on combined data, the pairwise genetic similarity coefficients (GSCs) among investigated individuals of the Tuyen Lam population were between 0.841 and 0.985 with an average (AGSC) of 0.973. Pairs of RhC6 with RhC8, RhC16, RhC17, $\mathrm{RhC} 18$ were the most genetically dissimilar while pairs of RhC14-RhC18 and $\mathrm{RhC} 19-\mathrm{RhC} 20$ were the most genetically similar. In the Hon Nga population, GSCs values were between 0.727 and 1.000 with an $A G S C$ of 0.911 . The pair of RhB4-RhB18 was the most genetically different and the pair of RhB12-RhB13 was genetically similar in the Hon Nga population. Genetic similarity coefficients (GSCs) among investigated individuals of the Bidoup population were between 0.705 and 0.985 with an average (AGSC) of 0.895 ; pairs of RhA1RhA2 and RhA4-RhA5 were the highest genetically similar, and pairs of RhA6-RhA4; RhA6-RhA5; RhA6-RhA5 were the lowest genetically similar. At the species level, the pairwise genetic similarity coefficients of $60 \mathrm{R}$. moulmainense individuals investigated in this study were between 0.644 and 1.000 with an average of $A G S C=0.894$, and the pair of RhA6-RhC15 was the most genetically different and the pair of RhB12-RhB13 was genetically identical. Thus, when combining data from both used techniques, the only pair of RhB12-RhB13 individuals could not be distinguished.
Based on these obtained genetic similarity coefficients, the UPGMA dendrogram for the genetic relationship among individuals investigated in this study is shown in Figure 4.

Using combined data, the genetic differentiation among $R$. moulmainense populations was estimated to be $G_{S T S}=0.1735$ and the number of migrants was estimated as $N \mathrm{~m}=2.3824$ individuals per generation among these populations. According to the point of view of the systematics of genetic differentiation, $G_{S T S}=0.1735$ showed the large genetic differentiation of the investigated populations (De Vicente, 2003), and this differentiation was significantly low in comparison to the same genus natural populations including $R$. trifolium and $R$. aureum in the previous studies of $\mathrm{Xu}$ et al. (2017a) and Liu et al. (2012), but at a moderate level compared to seven deciduous Azalea species (Rhododendron spp. section Pentanthera) in the research of Chappell et al. (2008), and higher than two $R$. protistum var. giganteum populations in Gaoligong Mountain National Nature Reserve, China calculated based on AFLP markers (Wu et al., 2015) and six $R$. brachycarpum populations in Korea that were examined using allozyme markers (Lee et al., 2002). 


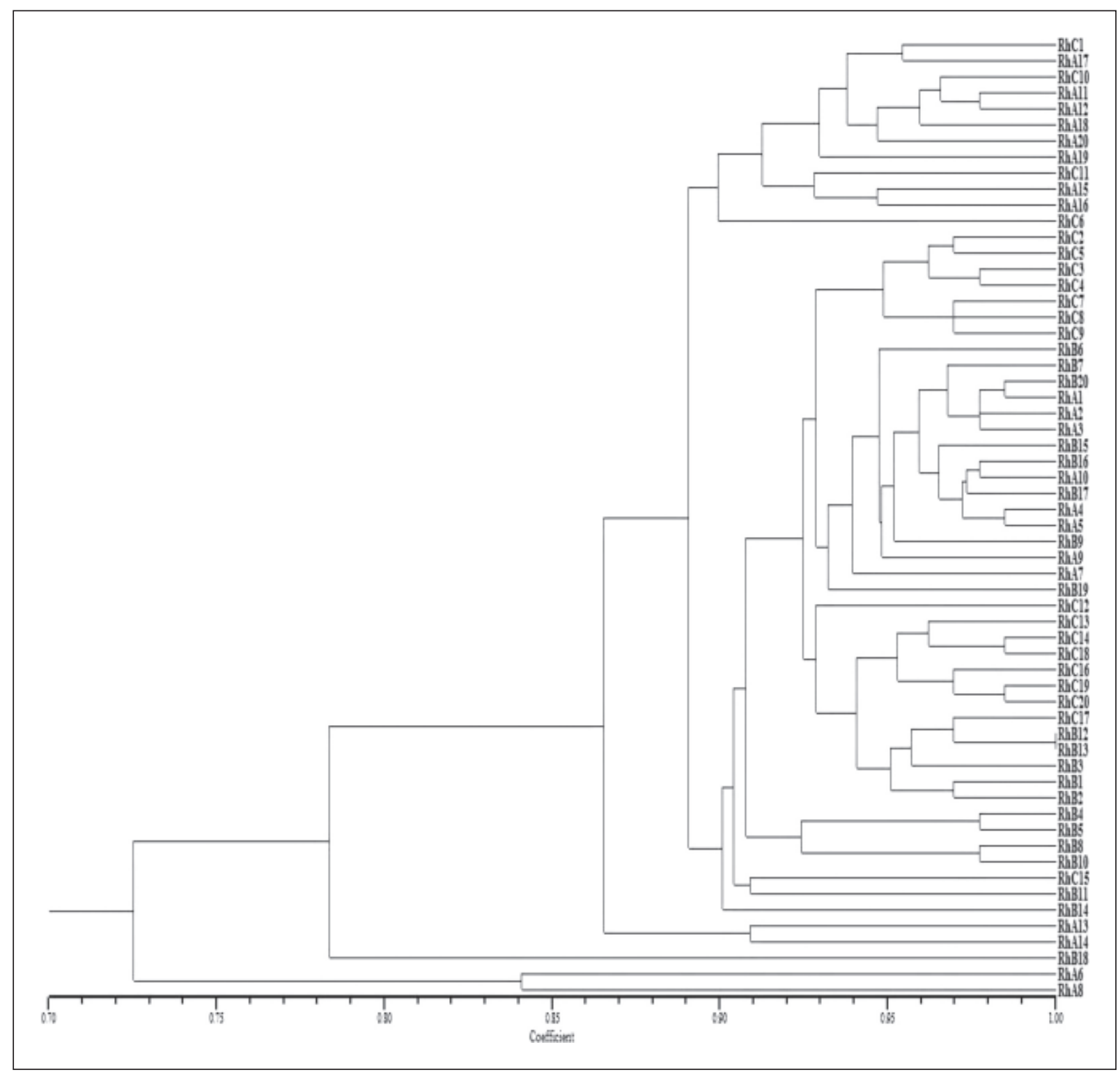

Fig. 4. Dendrogram for the genetic relationship among $R$. moulmainense individuals investigated in this study at species level based on combined data.

The large genetic differentiation of $R$. moulmainense populations in Lam Vien plateau lead to a genetic distance $(D)$ between Tuyen Lam and Hon Nga populations of 0.0399 , between Tuyen Lam 0.0621, and between Hon Nga Bidoup of 0.0607 . The geographic distance between Tuyen Lam population and Hon Nga population was about $27 \mathrm{kM}$; between Tuyen Lam population and Bidoup population was about $35 \mathrm{kM}$ and between Bidoup population and Hon Nga population was about 40 kM. The distance in a straight line from Bidoup population to Hon Nga population is further than to Tuyen Lam population, but the genetic distance between Bidoup and Hon Nga population was less than that of between Bidoup population and Tuyen Lam population (Figure 1). This can be explained by the existence of a densely settled urban area, DaLat City, between Bidoup and Tuyen Lam. The genetic relationship among the three investigated populations based on combined data is presented in Figure 5.

The genetic relationship among the three populations based on combined data was more similar to that based on ISSR than to the relationship based on SCoT. Based on combined data, AMOVA analysis revealed genetic differences among all three $R$. moulmainense populations, with $18 \%$ of total genetic variability portioned among populations and the remaining $82 \%$ portioned within populations. The proportion of genetic variance occurring within populations based on combined data was slightly higher than based on ISSR and substantially higher 


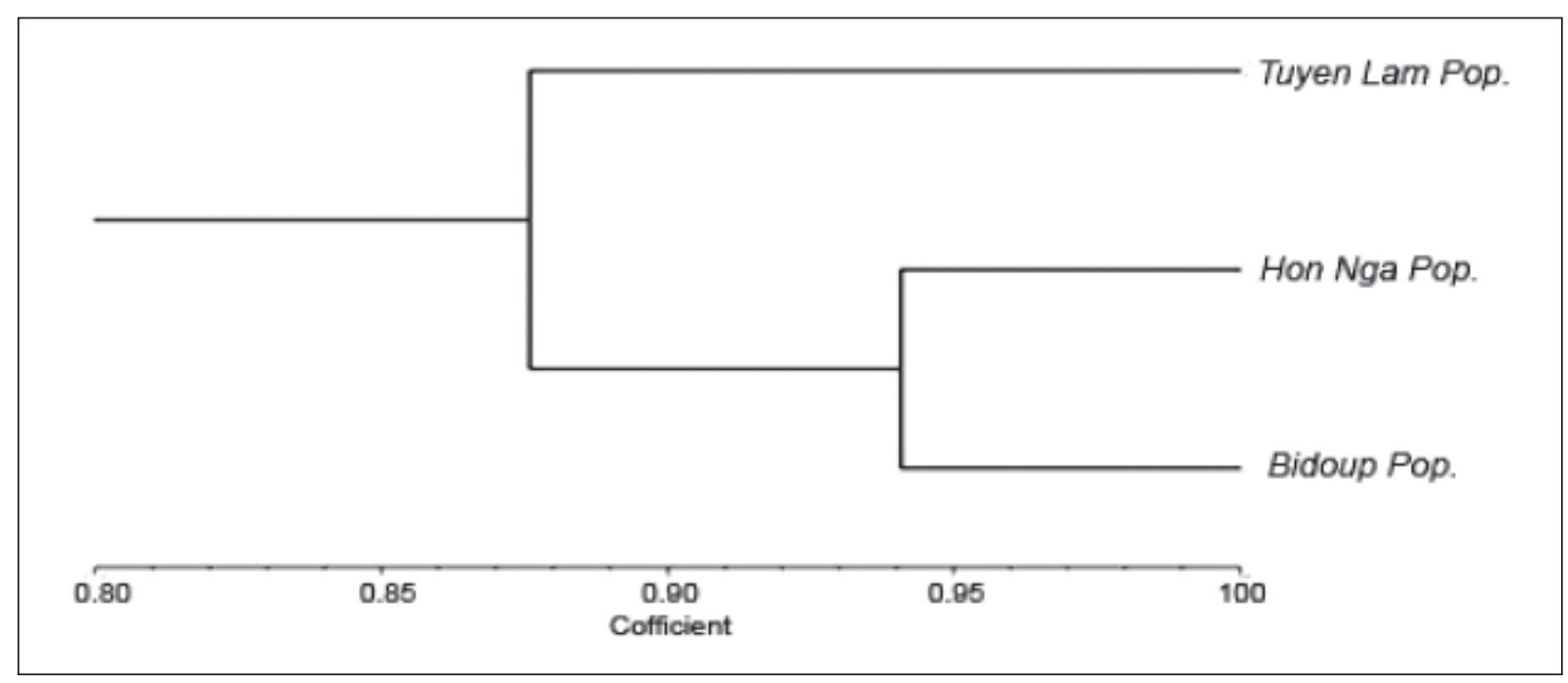

Fig. 5. Dendrogram representing the genetic relationship among three investigated populations based on combined data.

than that based on SCoT. But for all three types of data, the proportions of genetic variance among populations obtained in this study were higher than most previous studies on Rhododendron populations in the world including $R$. trifolium populations in Tibet (Xu et al., 2017a), R. aureum populations in China (Liu et al., 2012), R. protistum var. giganteum populations in China (Wu et al., 2015), R. nivale populations in Tibetan (Xu et al., 2017b), $R$. ferrugineum populations in Northern Apennines (Bruni et al., 2012).

\section{CONCLUSIONS}

The combination of data obtained from the two techniques helped to distinguish the individuals more clearly. The genetic diversity of the investigated $R$. moulmainense populations was lower in comparison to plant populations with similar life-history traits and many phylogenetically related populations, however, it was similar to or slightly higher compared to several other studies on other Rhododendron species. Genetic differentiation of the investigated populations was large according to the point of view of the systematics of genetic differentiation but may be larger, similar, or smaller comparing to other Rhododendron species. The proportion of genetic variance occurring within $R$. moulmainense populations was high compared with other Rhododendron populations worldwide. Genetic diversity, genetic differentiation, and genetic distance of investigated $R$. moulmainense populations may depend on human impacts on the habitats of this species.

The genetic diversity parameters based on combined data in this study can be applied for in-situ conservation of the $R$. moulmainense species in the Lam Vien plateau of Vietnam. For investigated populations, the ISSR technique was better than the SCoT technique in individual discriminatory ability, efficiency, and ability of the primer combination, but the SCoT primers were more efficient in reflecting genetic diversity of populations and differentiation among them.

\section{ACKNOWLEDGEMENTS}

The authors acknowledge the staff in the Bidoup National Park to help us with collections of DNA samples and Dr. Chris Harwood to check and revise English grammar. This study was funded by a Forest Gene Conservation Project of the Ministry of Agriculture and Rural Development.

\section{REFERENCES}

Admed, M.A. 2005. PCR based techniques - ISSR. Zagazig University, Zagazig. 4-19 pp.

Agarwal, A., Gupta, V., Haq, S.U., Jatav, P.K., Kothari, S.L. \& Kachhwaha, S. 2019. Assessment of genetic diversity in 29 rose germplasms using SCoT marker. Journal of King Saud University Science, 31(4): 780-788.

Amiryousefi, A., Hyvönen, J. \& Poczai, P. 2018. iMEC: Online Marker EfficiencyCalculator. Applications in Plant Sciences, 6(6): e1159.

Bruni, I., De Mattia, F., Labra, M., Grassi, F., Fluch, S., Berenyi, M. \& Ferrari, C. 2012. Genetic variability of relict Rhododendron ferrugineum L. populations in the Northern Apennines with some inferences for a conservation strategy. Plant Biosystems, 146(1): 24-32. 
Carling, M.D. \& Brumfield, R.T. 2007. Gene Sampling Strategies for Multi-Locus Population Estimates of Genetic Diversity. PLoS ONE, 2(1): e160.

Chappell, M., Robacker, C. \& Jenkins, T.M. 2008. Genetic diversity of seven deciduous Azalea species (Rhododendron spp. section Pentanthera) native to the Eastern United States. Journal of the American Society for Horticultural Science, 133(3): 374-382.

Chesnokov, Y.V. \& Artemyeva, A.M. 2015. Evaluation of the measure of polymorphism information of genetic diversity. Agricultural Biology, 50(5): 571-578.

Chi, V.V. 2012. Dictionary of Vietnamese Medicinal Plants. Medical Publishing House, Hanoi. 402 pp.

Collard, B.C.Y. \& Mackill, D.J. 2009. Start Codon Targeted (SCoT) polymorphism: A simple, novel DNA marker technique for generating gene-targeted markers in plants. Plant Molecular Biology Reporter, 27(1): 86-93.

De Vicente, M.C., Lopez, C. \& Fulton, T. 2003. Genetic Diversity Analysis with Molecular Marker Data: Learning Module. International Plant Genetic Resources Institute (IPGRI) and Cornell University. 17-23 pp.

Duy, N.V., Vinh, T.T., Cong, V.K., Hoi, Q.V., Tham, D.T., Huyen, N.T., Tien, T.V. \& Long, N.S. 2014. A synopsis and conservation status of the genus Rhododendron L. in Lam Dong province. Journal of Forestry Science, 2: 3334-3342.

Erfmeier, A. \& Bruelheide, H. 2011. Maintenance of High Genetic Diversity during Invasion of Rhododendron ponticum. International Journal of Plant Sciences, 172(6): 795-806.

Fang, R.C. \& Stevens, P.F. 2005. Ericaceae. In: Flora of China. Y.Z. Wu, P.H. Raven and D.Y. Hong (Eds.). Science Press, Beijing.

Hamrick, J.L. \& Godt, M.J.W. 1996. Allozyme diversity in cultivated crops. Crop Science, 37(1): 26-30.

Hogbin, P.M. \& Peakall, R. 1999. Evalution of the contribution of the genetic research to the management of the endangered plant Zieria prostrate. Conservevation of Biology, 13: 514522.

Huong, N.T.T. \& Hiep, N.T. 2012. New record of two species of Rhododendron L. (Ericaceae Juss.) for the flora of Vietnam. Journal of Biology, 34(4): 446-451.

Kumar, A., Mishra, P., Singh, S.C. \& Sundaresan, V. 2014. Efficiency of ISSR and RAPD markers in genetic divergence analysis and conservation management of Justicia adhatoda L., a medicinal plant. Plant Systematics and Evolution, 300(6): 1409-1420.
Kumar, P., Gupta, V.K., Misra, A.K., Modi, D.R. \& Pandey, B.K. 2009. Potential of Molecular Markers in Plant Biotechnology. Plant Omics Journal, 2(4): 141-162

Kuttapetty, M., Pillai, P., Varghese, R. \& Seeni, S. 2014. Genetic diversity analysis in disjunct populations of Rhododendron arboreum from the temperate and tropical forests of Indian subcontinent corroborate Satpura hypothesis of species migration. Biologia, 69(3): 311-322.

Lee, S.W., Kim, Y.M., Kim, W.W., Jang, S.S. \& Chung, J.M. 2002. Genetic variation and structure of Rhododendron brachycarpum D. Don, a rare and endangered tree species in Korea. Silvae Genetica, 51: 5-6.

Liu, Y.F., Xing, M., Zhao, W., Fan, R.J., Luo, S. \& Chen, X. 2012. Genetic diversity analysis of Rhododendron aureum Georgi (Ericaceae) located on Changbai Mountain using ISSR and RAPD markers. Plant Systematics and Evolution, 298(5): 921-930.

Muhammad, I. \& Muhammad, I. 2014. Molecular Markers in Plants for Analysis of Genetic Diversity: A Review. European Academic Research, 2(1): 1513-1540.

Nagoaka, T. \& Ogihara, Y. 1997. Applicability of inter-simple sequence repeat polymorphism in wheat for use as DNA markers in comparison to RFLP and RAPD markers. Theoretical and Applied Genetics, 93: 133-139.

Nybom, H. \& Bartish, I. 2000. Effects of life history traits and sampling strategies on genetic diversity estimates obtained with RAPD markers in plants. Perspectives in Plant Ecology Evolution Systematics, 3: 93-114.

Peakal, R. \& Smouse, P.E. 2006. GENALEX 6: Genetic analysis in Excel. Molecular Ecology, 6: 288-195.

Rohlf, F.J. 2004. NTSYSpc Numerical Taxonomy and Multivariate Analysis System Version 2.1 - User Guide. Appl. Bio. Inc.

Talebi, R., Nosrati, S., Etminan, A. \& Naji, A.M. 2018. Genetic diversity and population structure analysis of landrace and improved safflower (Cartamus tinctorious L.) germplasm using arbitrary functional gene-based molecular markers. Biotechnology \& Biotechnological Equipment, 32(5): 1183-1194.

Weising, K., Nybom, H., Wolff, K. \& Kahl, G. 2005. DNA Fingerprinting in Plants Principles, Methods, and Applications. 2nd Ed. Cpc Press Taylor \& Fancies group. 470 pp.

Williams, J.G.K., Kubelik, A.R., Livak, K.J., Rafalski, J.A. \& Tingey, S.V. 1990. DNA polymorphisms amplified by arbitrary primers are useful as genetic markers. Nucleic Acids Research, 18: 6531-6535. 
Wu, F.Q., Shen, S.K., Zhang, X.J., Wang, Y.H. \& Sun, W.B. 2015. Genetic diversity and population structure of an extremely endangered species: the world's largest Rhododendron. $A o B$ PLANTS, 7.

Xu, J.J., Zhao, B., Zhang, L.Y., Shen, H.F., Li, H.H. 2017b. Assessment of Genetic Diversity of Rhododendron nivale in Tibetan, China using AFLP Markers. Bulletin of Botanical Research, 37(1): 88-95.
Xu, J.J., Zhang, L.Y., Zhao, B. \& Shen, H.F. 2017 a. Assessment of genetic diversity among six populations of Rhododendron triflorum in Tibet using ISSR and AFLP markers. South African Journal of Botany, 108: 175-183.

Yeh, F.C., Yang, R.C. \& Boyle, T. 1999. POPGENE Version 1.32: Microsoft Window-Based Freeware for Population Genetics Analysis. University of Alberta, Edmonton. 